\title{
Pelatihan Mendesain Pembelajaran Berbasis Multimedia di Kalangan Guru MIN 11 Aceh Tenggara
}

\author{
*Harpan Reski Mulia \\ Madarasah Ibtidaiyah Negeri 11 Aceh Tenggara \\ *E-mail : harpanreskimulia@gmail.com \\ DOI: https://doi.org/10.21107/pangabdhi.v6i2.7602 \\ Naskah diterima 23 Juni 2020, Revisi 24 Juli 2020, Terbit 29 Oktober 2020
}

\begin{abstract}
Abstrak
Guru seyogianya melek dengan perkembangan teknologi terutama tentang teknologi yang mendukung proses pembelajaran, seperti pembuatan media pembelajaran dengan memanfaatkan teknologi. Microsoft Office Power Point, merupakan salah satu media yang bisa digunakan dalam mendesain pembelajaran yang lebih menarik. Karena, dengan bantuan Microsoft Office Power Point, guru dapat mendesain pembelajaran yang memadukan beberapa media, seperti audio, gambar, teks dan lain sebagainya atau disebut dengan multimedia. Untuk menanggulangi ketidak mampuan guru dalam mendesain pembelajaran berbasis multimedia tersebut, perlu diadakan pelatihan. Tulisan ini adalah eksplorasi kegiatan pelatihan yang dilakukan penulis terhadap kalangan guru di MIN 11 Aceh Tenggara. Hasil dari kegiatan tersebut menunjukkan bahwa, setiap guru di MIN 11 Aceh Tenggara sudah mempunyai laptop sebagai media untuk membuat Power Point, kendala yang dihadapi adalah cara pengoperasiannya yang belum bisa. Kemudian, setelah melakukan pelatihan tersebut guru merasa bahwa penggunaan Power Point sangat membantu dalam membuat pembelajaran yang menarik dan menyenangkan, dan siswa-siswa juga lebih antusias dan termotivasi dalam mengikuti pembelajaran, karena siswa merasa bahwa mereka seperti berada secara langsung dalam peristiwa-peristiwa yang dituangkan dalam Power Point.
\end{abstract}

Kata Kunci : guru, multimedia, optimalisasi

\begin{abstract}
Teachers should be able to respond to technological developments, especially about technologies that support the learning process, such as making learning media by utilizing technology. Microsoft Office PowerPoint, is one of the media that can be used in designing more interesting learning. Because, with the help of Microsoft Office PowerPoint, the teacher can design learning that combines several media, such as audio, images, text and so on or called multimedia. To overcome the inability of teachers to design multimedia-based learning, training needs to be held. This paper is an exploration of the training activities conducted by the author of teachers in MIN 11 Aceh Tenggara. The results of the activity showed that, every teacher in MIN 11 Aceh Tenggara already had a laptop as a medium for making PowerPoint, the obstacle faced was how to operate it that could not. Then, after doing the training the teacher felt that the use of PowerPoint was very helpful in making learning interesting and fun, and students were also more enthusiastic and motivated in participating in the learning, because students felt that they seemed to be directly in the events set forth in Power point.
\end{abstract}

Key Words: teacher, multimedia, and optimizing

\section{PENDAHULUAN}

Guru merupakan tenaga profesional yang mempunyai tugas utama mendidik, mengajar, membimbing, mengarahkan, melatih, menilai, dan mengevaluasipeserta didik pada pendidikan anak usia dini dan jalur pendidikan formal, pendidikan dasar dan pendidikan menengah (Bab 1 Pasal 1 Undang-Undang Republik Indonesia No 14 Tahun 2005 Tentang Guru Dan Dosen,
2005). UU ini, menjadi salah satu dasar atas pengembangan profesional guru dalam kaitannya melaksanakan proses pembelajaran. Karena, merancang proses pembelajaran yang efektif dan efisien sudah menjadi suatu keniscayaan bagi seorang guru.

Proses merancang pembelajaran tersebut di dalamnya terdapat beberapa komponen yang salah satunya adalah media pembelajaran. Media 
pembelajaran ini penting untuk diperhatikan, karena dengan menggunakan media pembelajaran dapat membantu peserta didik untuk memahami konsep-konsep yang abstrak (Smaldino et.al, 2005). Selain itu penggunaan media pembelajaran juga dapat mengatasi keterbatasan indera, ruang dan waktu, terkhusus lagi media dalam pembelajaran dapat meningkatkan dan mengarah perhatian siswa sehingga menimbulkan motivasi belajar siswa lebih tinggi (Arsyad, 2009).

Dewasa ini, pembuatan media dalam pembelajaran dianggap lebih mudah dan lebih menarik dibandingkan dengan masa lampau, dikarenakan media pembelajaran pada abad ke21 ini lebih menggunakan media berbasis elektronik (seperti komputer/laptop). Sehingga, bisa menggabungkan beberapa media (multimedia), dengan penggunaan multimedia tersebut pembelajaran lebih menarik dan menyenangkan.

Pembelajaran berbasis multimedia sangat bermanfaat dalam menunjang proses pembelajaran dikarenakan, pembelajaran berbasis multimedia dapat memahami gaya belajar anak (Mulia, 2019), selain itu multimedia yang di desain dengan baik juga dapat meningkatkan hasil belajar peserta didik (Butcher, 2006; Moreno \& Mayer, 1999; Moreno \& Valdez, 2005), bahkan pembelajaran berbasis multimedia, konsep fisikal yang abstrak bisa memberikan pemahaman kepada siswa(Gunawan et. al, 2014; Gunawan, Harjono, \& Imran, 2016).

Multimedia yang dimaksudkan adalah merujuk kepada pendapat Richard E. Mayer, yaitu bisa gabungan dari beberapa alat seperti komputer/laptop, monitor, speker dan lain-lain, dan bisa berupa beberapa media seperti gambar, audio, teks dan lain sebagainya (Mayer, 2009). Namun pada tulisan ini multimedia tersebut lebih menekankan kepada mendesain gambar, audio, teks, video menggunakan aplikasi Microsoft Office PowerPoint, walaupun dalam pengoperasiannya nantinya menggunakan beberapa alat seperti laptop, in-focus (LCD), speaker dan lain-lain. Sebagaimana meminjam pendekatan yang digunakan Mayer dalam pengembangan multimedia adalah learned centered approach bukan technology centered approach (Mayer, 2009).

Perlu penulis jelaskan bahwa, penulis di MIN 11 adalah CPNS dari bulan maret 2019. Bedasarkan hasil pengamatan penulis mulai mengajar di Madrasah ini, banyak siswa yang kurang tertarik saat berlangsung pembelajaran, dan hemat penulis karena guru masih menggunakan metode klasikal seperti ceramah terus menerus atau hanya memberikan siswa bahan bacaan. Selanjutnya, dari hasil wawancara penulis dengan guru-guru bahwa guru-guru belum bisa mendesain pembelajaran berbasis multimedia.

Untuk itu, salah satu cara dalam menghadapi masalah tersebut adalah memberikan pelatihan dalam upaya menunjang profesionalisme guru sebagai garda terdepan dalam pendidikan (Riskiawan et.al, 2016). Setelah pelatihan ini selesai, diharapkan 1) meningkatnya pengetahuan guru tentang pembelajaran berbasis multimedia; 2) meningkatnya pengetahuan guru dalam memanfaatkan internet untuk mencari bahan pembelajaran; 3) Guru termotivasi untuk menerapkan pembelajaran berbasis multimedia di dalam kelas

\section{METODE}

Pelaksanan pelatihan ini bekerja sama dengan Kanwil Aceh, khususnya tim pelaksana Latihan Dasar Calon Pegawai Negeri Sipil 2019 (Latsar CPNS). Waktu pelatihan ini secara khusus selama out-campus satu bulan, berupa pengabdian kepada masyarakat dalam hal ini adalah satuan kerja penulis yaitu MIN 11 Aceh Tenggara.

Berdasarkan observasi dan wawancara langsung kepada guru-guru, diperoleh beberapa hambatan dalam melaksanakan pelatihan ini, yaitu: (1) masih banyak guru yang belum mempunyai aplikasi Microsoft Office PowerPoint 2013 dan/atau beberapa guru mempunyai aplikasinya. Untuk memudahkan dalam pelaksanaan pelatihan ini dan menyesuaikan dengan modul yang ditulis, penulis menginstal aplikasi tersebut dan/atau mengupgrade aplikasi yang dimiliki; (2) Masih banyak guru yang memang sama sekali tidak tahu aplikasi ini dan/atau, guru yang tahu tapi sama sekali belum pernah menggunakannya, dengan demikian penulis harus memulai dari pengenalan aplikasi Microsoft Office PowerPoint 2013; (3) Bahkan beberapa guru memang tidak pernah mengoperasikan laptop/komputer. Namun, karena ada kebijakan dari kantor Kementerian Agama Aceh Tenggara, bahwa setiap guru wajib mempunyai laptop, maka tidak satu orangpun guru di Madrasah ini tidak mempunyai laptop. 
Tabel 1. Tahapan Pelaksanaan Pelatihan

\begin{tabular}{|c|c|c|}
\hline No & Kegiatan & Tahapan \\
\hline 1. & $\begin{array}{l}\text { Sebelum } \\
\text { Melaksanakan } \\
\text { Pelatiahan }\end{array}$ & $\begin{array}{l}\text { - Koordinasi dengan mentor tentang rencana pengadaan pelatihan ini. } \\
\text { - Pembuatan surat tentang pengadaan pelatihan ini, tertuju kepada Kepala MIN } \\
11 \text { Aceh Tenggara. } \\
\text { - Koordinasi dengan kepala madrasah. } \\
\text { - Membuat materi pelatihan, berupa modul Mic. Office PowerPoint } 2013 \text {. } \\
\text { - Menyiapkan bahan-bahan pelatihan. }\end{array}$ \\
\hline 2. & $\begin{array}{l}\text { Pemaparan Materi } \\
\text { Pelatihan } \\
\text { Pembelajaran } \\
\text { Berbasis Multimedia }\end{array}$ & $\begin{array}{l}\text { - Memaparkan materi Pelatihan Pembelajaran Berbasis Multimedia, dalam hal } \\
\text { ini menggunakan Sofware Mic. Office PowerPoint 2013, dan monitor. } \\
\text { - Metode pelatihan yang digunakan dalam pelatihan ini adalah ceramah, } \\
\text { demonstrasi, pendampingan, dan penugasan terstruktur. }\end{array}$ \\
\hline 3. & $\begin{array}{ll}\text { Evaluasi } & \text { Hasil } \\
\text { Pelatihan. } & \end{array}$ & $\begin{array}{l}\text { - Menentukan satu materi khusus yang akan didesain oleh tiap guru } \\
\text { pembelajaran berbasis multimedia. } \\
\text { - Menerapkan pembelajaran tersebut di ruang kelas. } \\
\text { - Metode yang digunakan dalam evaluasi ini adalah observasi dan wawancara } \\
\text { langsung kepada peserta tentang manfaat dan kekuarangan pelatihan ini. }\end{array}$ \\
\hline
\end{tabular}

Beranjak dari hambatan tersebut, kemudian dengan adanya pelatihan ini diharapkan guru dilingkungan MIN 11 Aceh Tenggara dapat memberikan tambahan wawasan dan pengetahuan tentang pemanfatan teknologi dalam menunjang proses pembelajaran yang lebih baik. Melalui pelatihan ini peserta juga diharapkan bisa mendesain pembelajaran yang lebih menyenangkan dengan mempertimbang ragam gaya belajar peserta didik. Melalui pelatihan ini, guru juga bisa memanfaatkan internet untuk mengambil bahan dalam mendesain pembelajaran berbasis multimedia dengan mempertimbangkan keakuratan, kredibilitas dan validitas bahan yang digunakan tersebut.

Pemberian tugas terstruktur ini berupa, setiap guru harus bisa mengajar dengan menggunakan multimedia yang telah desain dan menerapkan di dalam kelas sesuai dengan materi yang akan diajarkan. Selama pembuatan tugas ini, peserta diberikan kesempatan untuk bekerja sama dengan sesama peserta dan berkonsultasi dengan narasumber mengenai konten atau pembelajaran yang akan didesain dan diterapkan dalam proses pembelajaran di dalam kelas.

\section{HASIL DAN PEMBAHASAN}

Kegiatan yang dilakukan dalam pengabdian ini, diawali dengan pembukaan oleh kepala Madrasah untuk menjelaskan tujuan pelatihan ini. Sebagaimana dikemukakan diatas, pada awalnya tulisan ini adalah berupa laporan aktualisasi dalam Latsar CPNS 2019 yang diadakan di Banda Aceh selama 511 jam pelatihan atau \pm dua bulan, yang dibagi menjadi dua bagian yaitu in-campus selama \pm satu bulan dan out-campus \pm satu kampus.
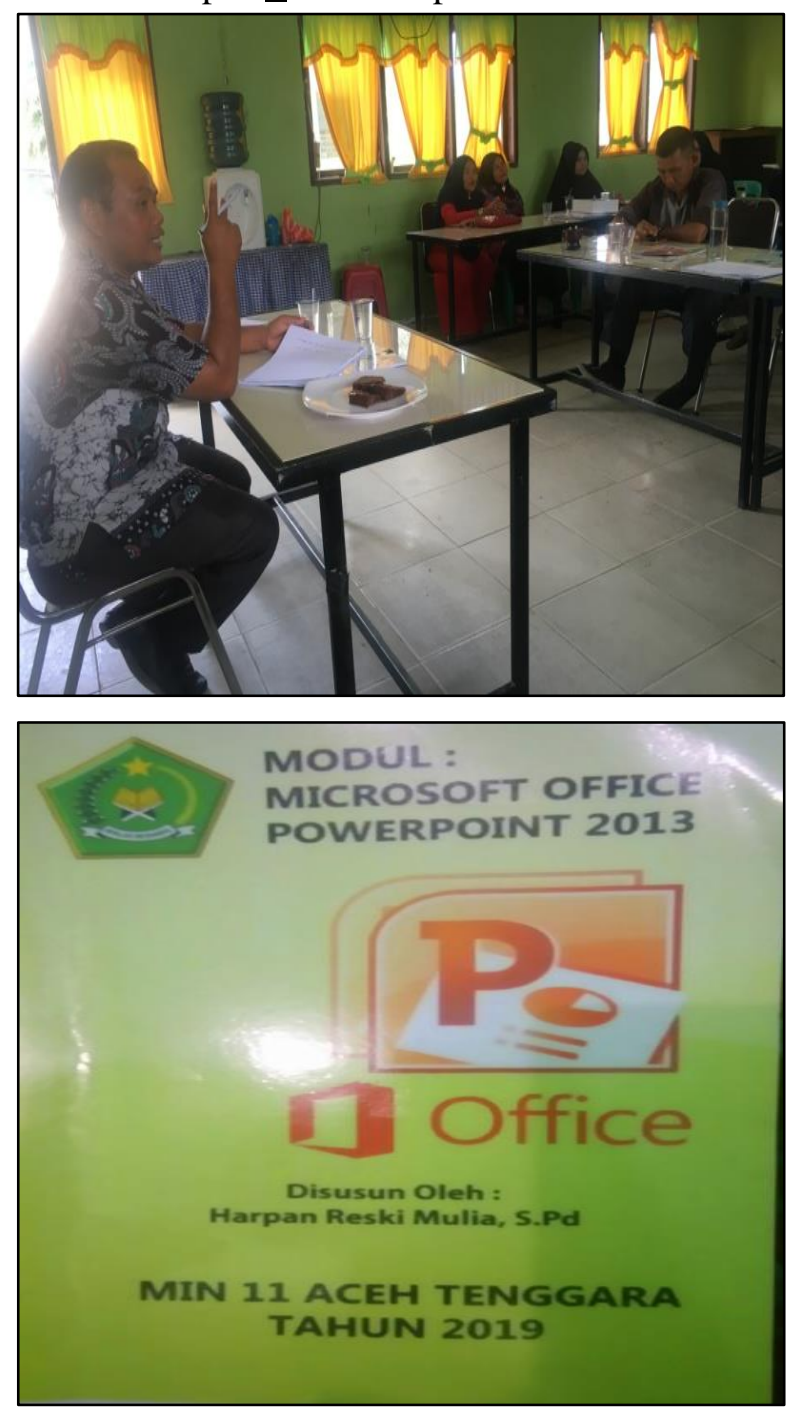

Gambar 1. Pembukaan Acara Pelatihan dan Modul Pelatihan 
Tabel 2. Realisasi Pelaksanaan Pelatihan

\begin{tabular}{|c|l|l|}
\hline No & \multicolumn{1}{|c|}{ Tanggal } & \multicolumn{1}{|c|}{ Materi } \\
\hline 1 & $\begin{array}{l}\text { Sabtu, 7 September 2019 } \\
\text { Durasi: } \pm \text { 60 menit. }\end{array}$ & $\begin{array}{l}\text { Pembukaan pelatihan dan penjelasan manfaat multimedia dan } \\
\text { memberikan contoh-contoh pembelajaran yang menggunakan } \\
\text { multimedia berupa video yang di ambil dari youtube, sekaligus } \\
\text { pembagian modul yang akan digunakan. }\end{array}$ \\
\hline 2 & $\begin{array}{l}\text { Jum'at, 13 September 2019 } \\
\text { Durasi: } \pm \text { 60 menit. }\end{array}$ & $\begin{array}{l}\text { Pengenalan tentang aplikasi yang akan digunakan dalam hal ini } \\
\text { adalah Mic. Office PowerPoint 2013. Yaitu seputar menu tools dan } \\
\text { manfaat-manfaatnya. }\end{array}$ \\
\hline 3 & $\begin{array}{l}\text { Sabtu, 14 September 2019 } \\
\text { Durasi: } \pm \text { 90 menit. }\end{array}$ & $\begin{array}{l}\text { Pendampingan palaksaan pelatihan lanjutan, seputar cara membuat } \\
\text { atau mendesain gambar berjalan pada Mic. Office PowerPoint 2013. }\end{array}$ \\
\hline 4 & $\begin{array}{l}\text { Jum'at, 20 September 2019 } \\
\text { Durasi: } \pm \text { 60 Menit }\end{array}$ & $\begin{array}{l}\text { Pendampingan palaksaan pelatihan lanjutan, seputar memanfaatkan } \\
\text { dan mengambil bahan-bahan dari internet untuk menunjang materi } \\
\text { dan mempertimbangkan sumber-sumber tersebut. }\end{array}$ \\
\hline 5 & $\begin{array}{l}\text { Sabtu, 21 September 2019 } \\
\text { Durasi: } \pm \text { 90 Menit }\end{array}$ & $\begin{array}{l}\text { Pendampingan palaksaan pelatihan lanjutan, sehingga menjadi } \\
\text { pembelajaran yang siap disajikan di dalam kelas. }\end{array}$ \\
\hline 6 & $\begin{array}{l}\text { 22-25 September 2019 } \\
\text { Durasi: 4 hari }\end{array}$ & $\begin{array}{l}\text { Pelaksaan evaluasi kegiatan, berupa aplikasi pelatihan yang guru } \\
\text { terapkan didalam kelas. }\end{array}$ \\
\hline
\end{tabular}

Gambar 1 ini menunjukkan bahwa kepala sekolah menjelaskan tujuan dari pelatihan ini dan memusyawarahkan jadwal pelatihan ini. Dari hasil diskusi yang dilakukan ini didapatkan hasil, bahwa pelatihan ini diadaakan dua hari dalam satu minggu yaitu hari jumat dan sabtu, pada hari jum'at pelatihan dilaksanakan dari jam 11:30 sampai 12:30 yaitu berkisar 60 menit. Sedangkan pada hari sabtu pelatihan ini dilaksanakan dari jam 12:00 sampai 13:30 berkisar 90 menit. Berhubung pelatihan ini juga untuk laporan Latsar penulis, maka kepala madarasah mewajibkan semua guru untuk hadir dan membawa laptop masing-masing. Berdasarkan penjelasan dari kepala madarasah ini juga, para guru sangat mengapresiasi dan mendukung sepenuhnya untuk berpartisipasi dalam pelatihan ini, karena mengingat pentingnya bagi guru untuk menguasai dan dapat mendesai pembelajaran berbasis multimedia, karena pembelajaran dengan menggabungkan gambar dan kata yang didatangkan secara bersamaan lebih efektif, jika dibandingkan dengan menggunakan gambar saja atau kata saja (Mayer \& Anderson, 1992).

Pelaksanaan pelatihan pada hari pertama ini yaitu pengenalan tentang aplikasi yang akan digunakan dalam hal ini adalah Mic. Office PowerPoint 2013. Diberikan pemaparan terlebih dahulu tentang menu tolls yang ada di Microsoft Office PowerPoint 2013 dengan alat bantu monitor untuk menanyangkan secara langsung dan modul yang telah dibagikan pada acara pembukaan pelatihan. Namun, untuk menjelaskan dan- mempraktikkannya guru-guru di depan laptop masing-masing, narasumber menggunakan metode demonstrasi dan saat bersamaan juga menggunakan metode ceramah karena dengan menggabungkan demonstrasi dan ceramah peserta lebih cepat memahami materi yang disampaikan (Febriansyah, 2017; Iswinar, 2019).

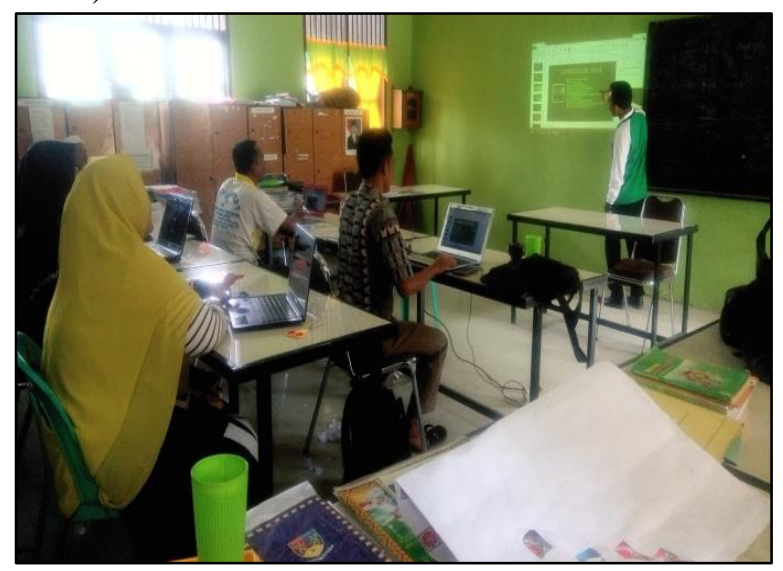

Gambar 2. Pelaksanaan Pelatihan

Kemudian, kegiatan dilanjutkan dengan pengenalan multimedia, dan memberikan/ menayangkan contoh-contoh pembelajaran yang menggunakan multimedia berupa video yang di ambil dari YouTube, sekaligus pembagian modul yang akan digunakan. Tujuan dari penampilan pembelajaran yang menggunakan multimedia ini, yaitu untuk memberikan motivasi kepada peserta tentang pentingnya melek teknologi terkhusus bagi guru, agar tercipta pembelajaran yang lebih efektif dan efesien, dan memperlihatkan bahwa dengan multimedia guru lebih mudah dalam menyajikan materi pelajaran kepada peserta didik. Kemudian, modul yang diberikan sebelum dimulai pelatihan ini dengan tujuan agar peserta dapat membaca dan lebih 
mudah memahami bahasa-bahasa yang digunakan dalam menu tools pada layar tampilan Microsoft Office PowerPoint 2013, sehingga diharapkan peserta nanti lebih mudah untuk memahami materi yang disajikan pada saat berlangsung pelatihan.

Gambar 2 ini menunjukkan para pelatih antusias dalam mengikuti pelatihan. Antusias dari para peserta, dapat dilihat dari cara mereka dalam mendengarkan dan memperagakan yang dijelaskan narasumber, serta tidak jarang bagi guru yang mungkin kurang faham, menulisnya dan kemudian menanyakan kembali kepada narasumber pada saat berlangsung penjelasan, dan/atau diakhir sesi penjelasan. Diantara peserta yang mengikuti pelatihan ini, hanya satu orang yang pernah menggunakan proyektor dalam pembelajaran, tetapi tidak menggunakan Microsoft Office PowerPoint 2013, proyektor tersebut hanya digunakan sebagai alat untuk menayangkan buku-buku pelajaran berbentuk pdf. Sementara itu, jika menggunakan Microsoft Office PowerPoint 2013 lebih dapat memberikan pemahaman pembelajaran bagi peserta didik (Achmadi et.al, 2014).

Pada hari kedua, pelatihan dilanjutkan dengan pendampingan palaksaan pelatihan lanjutan, yaitu seputar cara membuat atau mendesain gambar berjalan pada Microsoft Office PowerPoint 2013. Setelah narasumber memberikan penjelasan tentang menu-menu yang digunakan dalam mendesain gambar berjalan tersebut, selanjutnya narasumber mempraktikkan secara langsung yang kemudian diconvert dalam bentuk video (format MP4). Kendala yang dihadapi dalam pelaksana ini adalah peserta sulit dalam mengaplikasikan teori yang disampaikan narasumber. Setelah diadakan wawancara kepada peserta, maka dapat disimpulkan delapan dari sepuluh orang peserta belum membaca modul tentang materi tersebut, melihat kondisi tersebut narasumber kemudian memberikan waktu sepuluh menit untuk peserta membaca kembali modul yang telah diberikan, karena dalam berinteraksi dengan komputer, manusia harus menguasi teori terlebih dahulu sebelum mempraktikkan atau mengoperasikan komputer (Wardani \& Wijonarko, 2018,).

Setelah selesai membaca, beriringan dengan peserta mempraktikkan narasumber kembali menjelaskan materi tersebut. Sebagaimana dalam pelatihan yang dilakukan oleh Hendra Yufit Riskiawan, Dwi Putro Sarwo Setyohadi dan Aji Seto Arifianto di SMA Islam Al-Hidayah Jember bahwa untuk menghadapi kendala terbatasnya waktu dalam pelatihan tersebut, mereka terlebih dahulu memberikan materi pelatihan dan peserta membaca sehingga pendampingan pelatihan dapat berjalan dengan lancar (Riskiawan et.al, 2016). Dengan melihat kendala tersebut, dan melihat keberhasilan pelatihan yang dilakukan Riskiawan, dkk tersebut, sebelum menutup pertemuan, narasumber mengingatkan kepada peserta untuk membaca materi selanjutkan atau yang akan dipelajari pada hari selanjutnya, karena mengingat waktu yang terbatas dalam penelitian ini.

Pelatihan hari keempat, yaitu tentang memanfaatkan dan mengambil bahan-bahan dari internet untuk menunjang materi dan mempertimbangkan sumber-sumber tersebut. Pada pelatihan ini, kendala yang dialami tidak lagi tentang peserta belum membaca modul tersebut, tetapi pada laptop yang digunakan peserta belum menginstal sofware yang berfungsi untuk memudahkan mendownload sumbersumber yang dibutuhkan, dalam hal ini sofware yang digunakan adalah Internet Download Manager (IDM), agar tidak memakan waktu dalam menginstal aplikasi/sofaware tersebut, narasumber mengarahkan agar membuka situs https://id.savefrom.net/7/ pada new tab (jendela baru), karena kebanyakan bahan yang diperlukan adalah video-video yang berasal dari Youtube, yaitu video-video yang berkenaan dengan materi yang didesain seperti video-video sholawat pada pelajaran Sejarah Kebudayaan Islam materi Aku Rindu Padamu Ya Rasul, video organ gerak manusia pada pelajaran tematik tema Organ Gerak dan lain sebagainya, karena banyak hasi penelitian menunjukkan bahwa dengan menggunakan media video dapat menigkatkan hasil belajar siswa (Fasyi, 2015; Noviyanto et.al, 2015), motivasi belajar (Pebriani, 2017), dan keterampilan peserta didik (Ulfah \& Soenarto, 2017), bahkan terkait video YouTube sebagai media pembelajaran, lebih unggul dibandingkan dengan media riil dan media charta dalam menanamkan motivasi belajarkepada siswa (Iwantara et.al, 2014).

Hari kelima pelatihan, yaitu pendampingan kepada peserta untuk membuat materi pembelajaran yang siap disajikan di dalam kelas berbasis multimedia. Sebagaimana telah disampaikan kepada peserta diakhir sesi pelatihan hari keempat, bahwa pertemuan pada hari kelima ini peserta harus melihat materi yang akan didesain dan akan ditampilkan pada 
pembelajaran di kelas. Pada pertemuan ini para peserta sudah membawa berbagai sumber baik buku, file, video yang relevan dengan materi yang akan diajarkan, maka kendala yang dihadapi dalam pelatihan ini dinilai tidak seberat pada pelatihan hari-hari sebelumnya. Hanya saja, karena durasi waktu yang terbatas pada saat pelatihan pada hari-hari sebelumnya, banyak diantara peserta lupa materi-materi yang telah dipelajari. Namun, hambatan itu tidak menjadi kendala bagi peserta karena narasumber secara langsung mendampingi peserta. Pada hari ini juga, narasumber dan peserta mendiskusikan jadwal observasi atau narasumber secara langsung melihat hasil dari pelatihan ini berupa peserta mengaplikasikan dalam pembelajaran di dalam kelas yaitu pada hari senin sampai kamis (tanggal 22-25 September 2019).

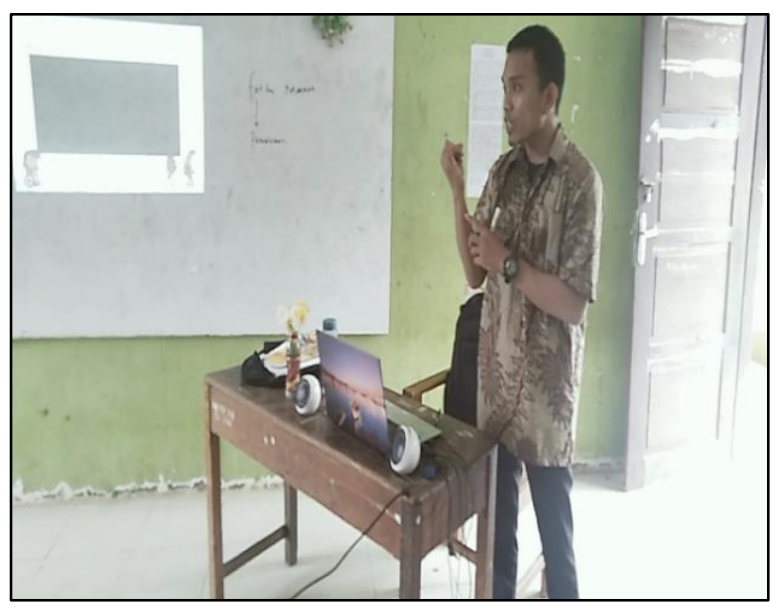

Gambar 3. Guru Menggunakan Multimedia dalam Pembelajaran

Sebagaimana telah dikemukakan diatas, bahwa evalusai program pelatihan ini dilakukan dengan observasi dan wawancara langsung kepada peserta pelatihan ini, maka gambar tiga ini menunjukkan bahwa guru telah mampu mendesai pembelajaran berbasis multimedia. Namun, secara umum hambatan guru dalam menggunakan multimedia pembelajaran di MIN 11 Aceh Tenggara adalah minimnya sarana seperti monitor dan screen (layar), sehingga ketika guru lain ingin menggunakan monitor, harus menunggu guru yang menggunakan tersebut selesai. Secara khusus hambatan guru dalam menggunakan multimedia adalah belum mahirnya mendesain pembelajaran tersebut, karena sebelum diadakan pelatihan ini, guru-guru belum pernah mendapatkan pelatihan terkait mendasain pembelajaran berbasis multimedia.

Berdasarkan wawancara yang dilakukan dengan peserta pelatihan, pelatihan ini telah memberikan pengetahuan bagi peserta tentang memfaatkan tool yang ada pada Microsoft Office PowerPoint 2013 dalam hal mendesaian pembelajaran.

Pelatihan ini juga telah memberikan stimulus bagi guru untuk selalu meng-upgrade kemampuannya dalam memanfaatkan media berbasis elektronik, sehingga dapat mendesain pembelajaran yang lebih menarik dan menyenangkan. Sebagaimana dilihat pada gambar tiga di atas, bahwa murid dinilai lebih antusias mengikuti pembelajaran, ditandai dengan tidak ada murid yang ribut atau tertidur ketika pembelajaran berlangsung.

\section{KESIMPULAN}

Kesimpulan yang dapat diperoleh dari kegiatan pelatihan mendesain pembelajaran berbasis multimedia ini adalah guru-guru MIN 11 Aceh Tenggara memahami dengan baik cara mendesain pembelajaran berbasis multimedia, dalam hal ini adalah dengan bantuan Microsoft Office PowerPoint. Guru-guru dapat mendesain pembelajaran berbasis multimedia dan mengambil berbagai bahan dari internet untuk dijadikan sebagai bahan dalam materi yang akan disajikan.

Hasil proses pelatihan ini menunjukkan bahwa guru-guru antusias dan mampu memotivasi kreativitas guru untuk menciptakan pembelajaran berbasis multimedia yang lebih kreatif dan memotivasi guru agar senantiasa berupaya mengembangkan profesionalisme nya. Para guru juga meminta kepada narasumber, untuk tetap melanjutkan pelatihan berbagai aplikasi yang dapat digunakan untuk mendesain pembelajaran yang lebih menarik, walaupun program latsar telah selesai.

\section{UCAPAN TERIMAKASIH}

Ucapan terimaksih kepada Kementerian Agama Republik Indonesia dan Kantor Wilayah Kementerian Agama Aceh Tenggara, seluruh panitia Latihan Dasar CPNS 2019 dan Balai Pendidikan dan Pelatihan Keagamaan Aceh, terkhusus kepada Yusnidar, S.Pd., M.Si dan Syuhermansah, S.Pd.I yeng telah banyak memberikan arahan dan masukan selama diadakan pelatihan ini.

\section{DAFTAR PUSTAKA}

Achmadi, H., Suharno, \& Suryani, N. 2014. Penerapan Model Assure Dengan Menggunakan Media Power Point Dalam 
Pembelajaran Bahasa Inggris Sebagai USAha Peningkatan Motivasi Dan Prestasi Belajar Siswa Kelas X MAN Sukoharjo Tahun Pelajaran 2012/2013. Jurnal Teknologi Pendidikan dan Pembelajaran. Vol 2 (1).

Arsyad, A. 2009. Media Pengajaran. Rajawali Pers.

Butcher, K. R. 2006. Learning from Text with Diagrams: Promoting Mental Model Development and Inference Generation. Journal of Educational Psychology. Vol 98 (1), 182-197. https://doi.org/10.1037/0022$\underline{0663.98 .1 .182}$

Fasyi, M. C. A. 2015. Pengaruh Penggunaan Media Video Terhadap Hasil Belajar IPA Siswa Kelas IV SD Negeri Ngoto Bantul Yogyakarta. Basic Education. Vol 4 (16). http://journal.student.uny.ac.id/ojs/ojs/index.p $\mathrm{hp} / \mathrm{pgsd} /$ article/view/1195

Febriansyah, F. 2017. Pengaruh Penerapan Metode Kombinasi Ceramah, Demonstrasi dan Latihan (CDL) Terhadap Hasil Belajar Komputer Akuntansi Siswa di SMK Negeri 1 Palembang Tahun Ajaran 2015/2016. Jurnal Neraca: Jurnal Pendidikan dan Ilmu Ekonomi Akuntansi. Vol 1 (1). https://jurnal.univpgripalembang.ac.id/index.php/neraca/article/vie $\underline{\mathrm{w} / 1166}$

Gunawan, G., Harjono, A., \& Imran, I. 2016. Pengaruh Multimedia Interaktif dan Gaya Belajar Terhadap Penguasaan Konsep Kelor Siswa. Jurnal Pendidikan Fisika Indonesia. Vol $12 \quad$ (2). $118-125 \quad$ pp. https://doi.org/10.15294/jpfi.v12i2.5018

Gunawan, Gunawan, Harjono, A., Sahidu, H., \& Sutrio, S. 2014. Penggunaan Multimedia Interaktif dalam Pembelajaran Fisika dan Implikasinya Pada Penguasaan Konsep Mahasiswa. Jurnal Pijar Mipa. Vol 9 (1). https://doi.org/10.29303/jpm.v9i1.38

Iswinar, I. 2019. Pendekatan Kontruktivistik Untuk Meningkatkan Kualitas Pembelajaran Komputer Akuntansi Kelas XI AK I SMK Negeri 1 Banda Aceh. Jurnal Serambi Akademica. Vol 7 (7). 951-958 pp. https://doi.org/10.32672/jsa.v7i7.1640

Iwantara, I. W., Sadia, W. M. P., \& Suma, M. S. 2014. Pengaruh Penggunaan Media Video Youtube dalam Pembelajaran IPA Terhadap Motivasi Belajar dan Pemahaman Konsep Siswa. Jurnal Pendidikan dan Pembelajaran
IPA Indonesia. Vol 4

(1).

http://119.252.161.254/e-

journal/index.php/jurnal_ipa/article/view/108 $\underline{1}$

Mayer, R. E. 2009. Multimedia Learning: Prinsip dan Aplikasi (T. W. Utomo, Trans.). Pustaka Pelajar.

Mayer, R. E., \& Anderson, R. B. 1992. The instructive animation: Helping students build connections between words and pictures in multimedia learning. Journal of Educational Psychology. Vol 84 (4), 444-452 pp.

Moreno, R., \& Mayer, R. E. 1999. MultimediaSupported Metaphors for Meaning Making in Mathematics. Cognition and Instruction. Vol 17 (3). 215-248 pp. https://doi.org/10.1207/S1532690XCI1703_1

Moreno, R., \& Valdez, A. 2005. Cognitive load and learning effects of having students organize pictures and words in multimedia environments: The role of student interactivity and feedback. Educational Technology Research and Development. Vol 53 (3), 3545 pp. https://doi.org/10.1007/BF0250479

Mulia, H. R. 2019. Pembelajaran Berbasis Multimedia: Upaya Memahami Keberagaman Gaya Belajar Anak. Jurnal Penjaminan Mutu, Vol 5 (2), 144-154 pp. https://doi.org/10.25078/jpm.v5i2.857

Noviyanto, T. S. H., Juanengsih, N., \& Rosyidatun, E. S. 2015. Penggunaan Media Video Animasi Sistem Pernapasan Manusia Untuk Meningkatkan Hasil Belajar Biologi. EDUSAINS. Vol 7 (1). 57-63 pp. https://doi.org/10.15408/es.v7i1.1215

Pebriani, C. 2017. Pengaruh penggunaan media video terhadap motivasi dan hasil belajar kognitif pembelajaran IPA Kelas V. Jurnal Prima Edukasia. Vol 5 (1). 11-21 pp. https://doi.org/10.21831/jpe.v5i1.8461

Riskiawan, H. Y., Setyohadi, D. P. S., \& Arifianto, A. S. 2016. Pelatihan Pengembangan Media Pembelajaran Berbasis Multimedia Untuk Meningkatkan Kualitas dan Kreativitas Guru SMA. JDinamika. Vol 1 (1). https://doi.org/10.25047/j-dinamika.v1i1.134

Smaldino, S. E., Russel, J. D., Robert, H., \& Molenda, M. 2005. Instructional Technology 
and Media for Learning (8th ed). Wardani, T. I., \& Wijonarko. 2018. Pengaruh Pearson/Merrill/Prentice Hall.

Model Pembelajaran Kooperatif Tipe

Ulfah, D. M., \& Soenarto, S. 2017. Pengaruh Penggunaan Media Video dan Gambar Terhadap Keterampilan Menulis Kelas V. Jurnal Prima Edukasia, Vol 5 (1), 22-34 pp. https://doi.org/10.21831/jpe.v5i1.7693

Undang-Undang Republik Indonesia No 14 Tahun 2005 Tentang Guru dan Dosen. (2005).

https://jdih.kemenkeu.go.id/fullText/2005/14 TAHUN2005UU.htm Investigasi Kelompok Berbasis Lokakarya Terhadap Pemahaman Petunjuk Operasional Komputer Multimedia dan Kemampuan Mengoperasikan Komputer Multimedia Visual Basic. In Prosiding Seminar Nasional Geotik 2018: Literasi Digital untuk Pendidikan Aman Berkelanjutan (pp. 265271). Pendidikan Teknik Informatika dan Pendidikan Geografi Fakultas Keguruan dan Ilmu Pendidikan Universitas Muhammadiyah Surakarta. 